Article

\title{
Dependence of the Physical Properties and Molecular Dynamics of Thermotropic Liquid Crystalline Copolyesters on $p$-Hydroxybenzoic Acid Content
}

\author{
Gi Tae Park ${ }^{1}$, Won Jun Lee ${ }^{1}$, Jin-Hae Chang ${ }^{1, *}$ and Ae Ran Lim ${ }^{2,3, *}$ \\ 1 Department of Polymer Science and Engineering, Kumoh National Institute of Technology, Gumi 39177, \\ Korea; pkgt0129@naver.com (G.T.P.); wns2536@naver.com (W.J.L.) \\ 2 Analytical Laboratory of Advanced Ferroelectric Crystals, Jeonju University, Jeonju 55069, Korea \\ 3 Department of Science Education, Jeonju University, Jeonju 55069, Korea \\ * Correspondence: changjinhae@hanmail.net (J.-H.C.); $\operatorname{arlim@jj.ac.kr~(A.R.L.)~}$
}

Received: 29 November 2019; Accepted: 10 January 2020; Published: 12 January 2020

\begin{abstract}
Two series of thermotropic liquid crystal copolymers (TLCPs) with different monomer structures and compositions were synthesized. The copolymers in the first series consisted of 2,5-diethoxyterephthalic acid (ETA), hydroquinone (HQ), and p-hydroxybenzoic acid (HBA), whereas those in the second series contained ETA, 2,7-dihydroxynaphthalene (DHN), and HBA. In both series, the molar ratio of HBA to the other monomers varied from 0 to 5 . The thermal properties, degree of crystallinity, and stability of the liquid crystalline mesophase of the copolymers obtained at each HBA ratio were evaluated and compared. Overall, at each HBA content, the DHN-containing copolymer had better thermal properties, but the HQ-containing copolymer exhibited a higher degree of crystallinity and a more stable liquid crystalline mesophase. Furthermore, similar thermal stabilities were observed in both series. The dependence of the molecular dynamics of the TLCPs on the monomer structure was explained using ${ }^{13} \mathrm{C}$ magic-angle spinning/cross-polarization nuclear magnetic resonance spectroscopy. An in-depth investigation of the relaxation time of each carbon revealed that the molecular motions of the TLCPs were greatly influenced by the structures of the monomers present in the main chain. The molecular dynamics of the HQ and DHN monomers in the two series were evaluated and compared.
\end{abstract}

Keywords: thermotropic liquid crystalline copolymer; $p$-hydroxybenzoic acid; thermal property; ${ }^{13} \mathrm{C}$ solid-state nuclear magnetic resonance spectroscopy; molecular dynamics

\section{Introduction}

Thermotropic liquid crystal polymers (TLCPs), which contain a special monomer chemical structure, are already widely used as high-performance commercial engineering polymers owing to their good thermal properties, high strength, high modulus, low viscosity, and other excellent mechanical properties [1,2]. Many studies have correlated the structures of TLCPs with their characteristics [3-5]. In particular, compared with liquid crystalline polyamides, which exhibit lyotropic properties, heat-releasing liquid crystalline polyesters have attracted much attention because of their ease of melting, despite their inferior physical strength [6,7].

Although interest in TLCPs and their composites has been increasing, to achieve enhanced physical properties, most studies have focused on rigid rod-type TLCPs with completely aromatic monomers in the main chain $[8,9]$. In almost all TLCPs, the thermo-mechanical properties have been enhanced by using straight, rigid rod-shaped monomer units, including terephthalic acid (TPA), hydroquinone (HQ), 4,4'-biphenol (BP), p-hydroxybenzoic acid (HBA), 6-hydroxy-2-naphthoic acid (HNA), naphthalenediol 
derivatives, and naphthalenedicarboxylic acid isomers [9-13]. If the basic structure is substituted with a para-substituted carboxyl group or benzene ring, homopolyesters synthesized from monomers such as TPA, HQ, and HBA typically melt at approximately $600^{\circ} \mathrm{C}$ [12]. Although rigid rod-type TLCPs exhibit excellent thermal and mechanical properties, their high melting points generally make processing difficult $[6,14]$. These TLCPs also show low solubilities in common solvents. As a result, many studies have investigated the introduction of substituents, flexible alkyl groups, or side-group TLCPs [15-17]. The use of a monomer with a flexible alkyl unit or kinked monomer structure in the main chain or a bulky substituent in the aromatic ring can decrease the melting point of the TLCP to $400{ }^{\circ} \mathrm{C}$ or lower, which makes melting or injection molding possible $[4,18]$. In addition, the melting point can be greatly reduced by using asymmetric monomers or by copolymerizing monomers with different structures such as HBA and HNA $[19,20]$. If the copolymer is synthesized using a well-designed monomer, it can be easily processed, and lowering the processing temperature can expand its applicability. For example, a structure with a flexible alkyl moieties as side groups or meta-substituted monomer units can provide significantly increased processability. Disadvantageously, this improvement in processability is often accompanied by a significant deterioration of the thermo-mechanical properties.

The measurement of ${ }^{13} \mathrm{C}$ nuclear magnetic resonance (NMR) chemical shifts is the best method to identify synthesized chemical structures. In addition, ${ }^{13} \mathrm{C}-\mathrm{NMR}$ relaxation times in the rotating frame spin-lattice $\left(T_{1 \rho}\right)$ for ${ }^{13} \mathrm{C}$ nuclei, which have low natural abundance, are affected by dipolar interactions with directly bonded hydrogens [21]. Therefore, the determination of the relaxation values of nuclei in different environments in the chemical structure can provide information on the molecular motion occurring in each part of the structure. The ${ }^{13} \mathrm{C}-\mathrm{NMR} T_{1 \rho}$ values are particularly informative because they are directly related to the motion of each carbon in the $\mathrm{kHz}$ frequency range. ${ }^{13} \mathrm{C}-\mathrm{NMR}$ $T_{1 \rho}$ results obtained using cross-polarization (CP) and magic-angle spinning (MAS) have been used to elucidate the molecular dynamics of various chemical structures [22,23]. Therefore, the determination of ${ }^{13} \mathrm{C}$-NMR $T_{1 \rho}$ values is the best method for studying the molecular dynamics of individual ${ }^{13} \mathrm{C}$ atoms in a chemical structure.

The objectives of this study were to: (1) synthesize a two copolymer series using 2,5-diethoxyterephthalic acid (ETA), HBA, and two different diol monomers, namely, HQ and 2,7-dihydroxynaphthalene (DHN); (2) study the effect of the HBA unit on the properties of the ETA/HQ and ETA/DHN copolymers by varying the HBA molar ratio (0-5); and (3) study the molecular dynamics of the two copolymer series using ${ }^{13} \mathrm{C}$ solid-state NMR spectroscopy.

The copolymers were synthesized using ETA, which contains dialkoxy side groups, and DHN, which is a kinked monomer, to lower the values the glass transition temperature $\left(T_{g}\right)$, melt transition temperature $\left(T_{m}\right)$, and isotropization temperature $\left(T_{i}\right)$. Both ETA and DHN have very poor thermal properties, and to compensate for this disadvantage, para-substituted HBA was also used as a monomer. The thermal properties, thermal stability, liquid crystalline mesophase, degree of crystallinity, and molecular dynamics of the synthesized copolymers were investigated while varying the molar ratio of HBA from 0 to 5 . In addition, the effect of the molar ratio of HBA on the structures of the polymers in each series was investigated using ${ }^{13} \mathrm{C}-\mathrm{NMR}$ spectroscopy. The $T_{1 \rho}$ value for each carbon of the dialkoxy groups, $\mathrm{C}=\mathrm{O}$ groups, and TPA, HQ, naphthalene, and HBA rings in the two series (TLCP-I and -II) was obtained to understand the molecular dynamics. In addition, the dependence of molecular motions on the molar ratio of HBA was investigated using the relaxation times, and the effect of the molar ratio of HBA on carbon mobility was discussed.

\section{Materials and Methods}

\subsection{Materials}

All reagents used in this study were purchased from Aldrich Chemical Co. (Yongin, Korea) or TCI (Seoul, Korea) and were used as received. However, common solvents were purified by distillation. 


\subsection{Syntheses of Monomers}

The chemical structures of all the monomers (1-5) for the TLCP syntheses are shown in Figure 1. The monomers were synthesized via several routes [24].

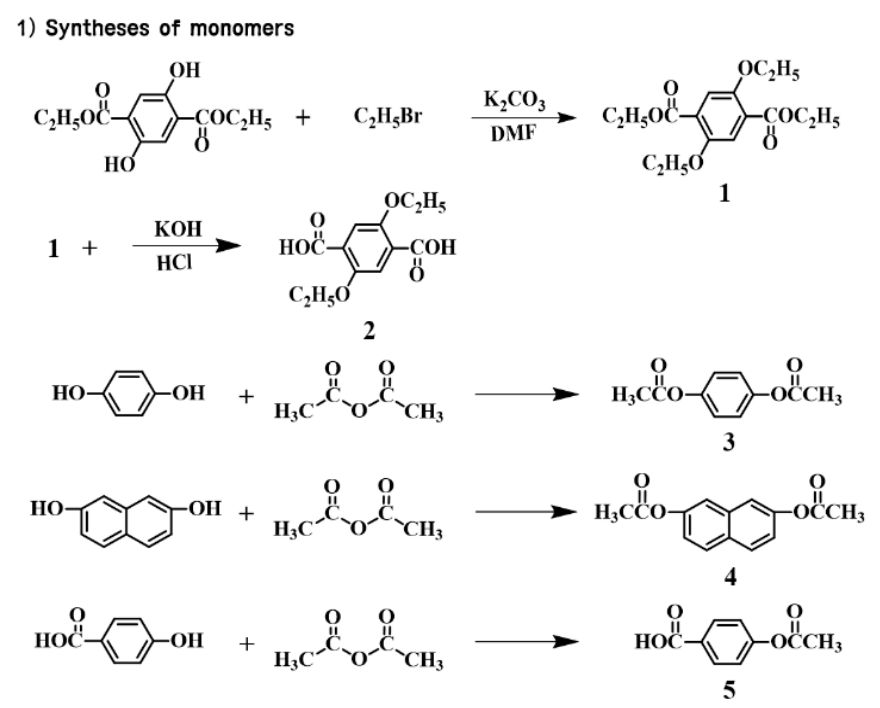

2) Syntheses of TLCPS

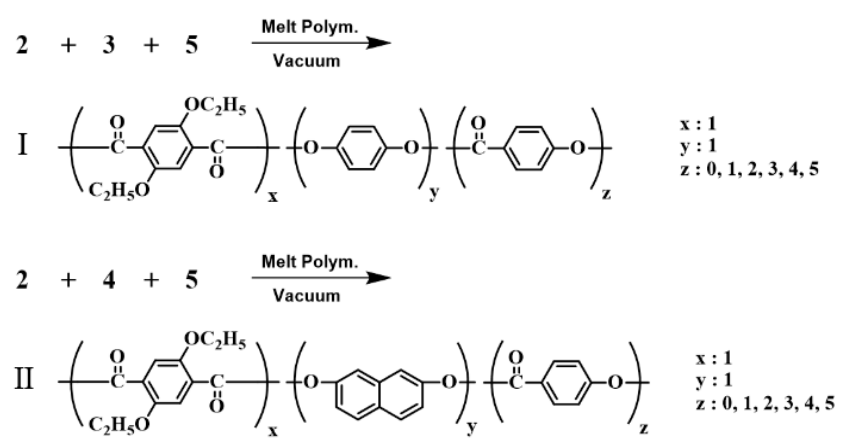

Figure 1. Synthetic routes of the thermotropic liquid crystalline polymers.

\subsection{Synthesis of TLCP-I}

The TLCPs were synthesized by a melt polymerization method [25]. The monomer composition of the TLCP-I series is shown in Figure 1 and summarized in Table 1, and the detailed reaction conditions are shown in Table 2. The same synthetic procedure was used to produce each TLCP, independent of the monomer composition; therefore, the procedure for synthesizing sample I-C (2/3/5 = 1:1:2 (molar ratio)) is detailed here as a representative example. First, $25.42 \mathrm{~g}\left(1.0 \times 10^{-1} \mathrm{~mol}\right)$ of ETA (2), $19.42 \mathrm{~g}$ $\left(1.0 \times 10^{-1} \mathrm{~mol}\right)$ of 1,4-diacetoxybenzene (3), and $36.03 \mathrm{~g}\left(2.0 \times 10^{-1} \mathrm{~mol}\right)$ of 4-acetoxybenzoic acid (5) were placed in a polymerization tube. The mixture was heated under the conditions shown in Table 2 in a constant nitrogen flow. Acetic acid was formed during heating, and the polymerization was completed by lowering the pressure from 300 to 1 Torr as the final step.

The obtained solid product was cooled to room temperature, washed several times with acetone, and then dried in a vacuum oven at $80^{\circ} \mathrm{C}$ for $24 \mathrm{~h}$ to obtain TLCP-I. In most common solvents, the synthesized TLCP was not dissolved at all. In particular, it has not been dissolved at all in various mixed solvents, which have often been used to dissolve TLCP. In almost all common solvents, the synthesized TLCP was not dissolved at all. In particular, it did not dissolve at all in mixed solvents such as phenol/p-chlorophenol/1,1,2,2-tetrachloroethane $=25: 40: 35(\mathrm{w} / \mathrm{w} / \mathrm{w})$, which were frequently used for TLCP dissolution. As no dissolution was observed, the viscosity could not be measured, as indicated in Table 3. 
Table 1. Molar ratios of monomers in the TLCPs.

\begin{tabular}{ccccccc}
\hline & & \multicolumn{2}{c}{$\mathbf{I}^{\mathbf{a}}$} & \multicolumn{2}{c}{$\mathbf{I I}^{\mathbf{b}}$} \\
\cline { 2 - 7 } TLCP & ETA & HQ & HBA & ETA & DHN & HBA \\
\hline A & 1 & 1 & 0 & 1 & 1 & 0 \\
B & 1 & 1 & 1 & 1 & 1 & 1 \\
C & 1 & 1 & 2 & 1 & 1 & 3 \\
D & 1 & 1 & 3 & 1 & 1 & 4 \\
E & 1 & 1 & 4 & 1 & 1 & 5 \\
F & 1 & 1 & 5 & 1 & 1 & \\
\hline
\end{tabular}

${ }^{\mathrm{a}} \mathrm{x}$ : 2,5-diethoxyterephthalic acid (ETA), y: hydroquinone (HQ), z: $p$-hydroxybenzoic acid (HBA). ${ }^{\mathrm{b}} \mathrm{x}: \mathrm{ETA}, \mathrm{y}$ :

2,7-dihydroxynaphthalene (DHN), z: HBA.

\subsection{Synthesis of TLCP-II}

The same synthetic procedures were used to produce each TLCP; therefore, we describe here the preparation of sample II-C (2/4/5 $=1: 1: 2$ (molar ratio)) as a representative example. TLCP-II was synthesized using $25.42 \mathrm{~g}\left(1.0 \times 10^{-1} \mathrm{~mol}\right)$ of ETA $(2), 24.42 \mathrm{~g}\left(1.0 \times 10^{-1} \mathrm{~mol}\right)$ of 2,7-diacetoxynaphthalene (4), and $36.03 \mathrm{~g}\left(2.0 \times 10^{-1} \mathrm{~mol}\right)$ of 4-acetoxybenzoic acid (5). As a final step to complete the polymerization, the pressure was lowered from 240 to 1 Torr. The subsequent steps were the same as those described for TLCP-I. The monomer composition of TLCP-II is shown in Figure 1 and summarized in Table 1, and the detailed reaction conditions are shown in Table 2. As described for the TLCP-I series, the solubility of each polymer in the TLCP- II series was examined using a mixture of three solvents. No dissolution was observed; hence, the viscosity was not measured (Table 3).

\subsection{NMR Spectroscopy}

Powdered samples were inserted into $4 \mathrm{~mm}$ diameter zirconia rotors and then spun at fsufficient speed to avoid the overlap of spinning sidebands. ${ }^{13} \mathrm{C}-\mathrm{NMR}$ (Brucker, Berlin, Germany) $T_{1} \rho$ values were measured by varying the duration of the ${ }^{13} \mathrm{C}$ spin-locking pulse [26]. The typical experimental approach assumes the use of $\mathrm{CP}$ from protons to enhance ${ }^{13} \mathrm{C}$ sensitivity. The width of the $\pi / 2$ pulse used to measure the ${ }^{13} \mathrm{C}$-NMR $T_{1 \rho}$ values was $3.3 \mu \mathrm{s}$. The decay of the ${ }^{13} \mathrm{C}$ magnetization in the spin-locking field was followed for spin-locking times of up to $160 \mathrm{~ms}$.

\subsection{Characterization}

The thermal properties of the copolymers were determined by differential scanning calorimetry (DSC), and thermogravimetric analysis (TGA), which were conducted under a $\mathrm{N}_{2}$ atmosphere using DuPont 910 equipment (New Castle, DE, USA). The samples were heated or cooled at a rate of $20^{\circ} \mathrm{C} / \mathrm{min}$. Wide-angle X-ray diffraction (XRD) measurements were performed at room temperature on a Rigaku (D/Max-IIIB) X-ray diffractometer (Tokyo, Japan) using Ni-filtered $\mathrm{Cu}-\mathrm{K} \alpha$ radiation. The scanning rate was $2^{\circ} /$ min over a $2 \theta$ range of $2-35^{\circ}$. A polarizing microscope (Leitz, Ortholux, Lahn-Dill-Kreis, Germany) equipped with a Mettler FP-5 hot stage was used to examine the liquid crystalline behavior. The ChemDradfsw (Bitek Chems. Inc., Seoul, Korea) computer simulation program was used to investigate the three-dimensional (3-D) polymer structures.

The ${ }^{13} \mathrm{C}$ NMR chemical shifts and $T_{1} \rho$ values were obtained by ${ }^{13} \mathrm{C} C \mathrm{CP} / \mathrm{MAS}$ NMR spectroscopy at a Larmor frequency of $\omega_{0} / 2 \pi=100.61 \mathrm{MHz}$ using Bruker 400 DSX NMR spectrometers at the Korea Basic Science Institute, Western Seoul Center, Seoul, Korea. The chemical shifts are referenced to tetramethylsilane (TMS). 
Table 2. Melt polymerization conditions of TLCPs.

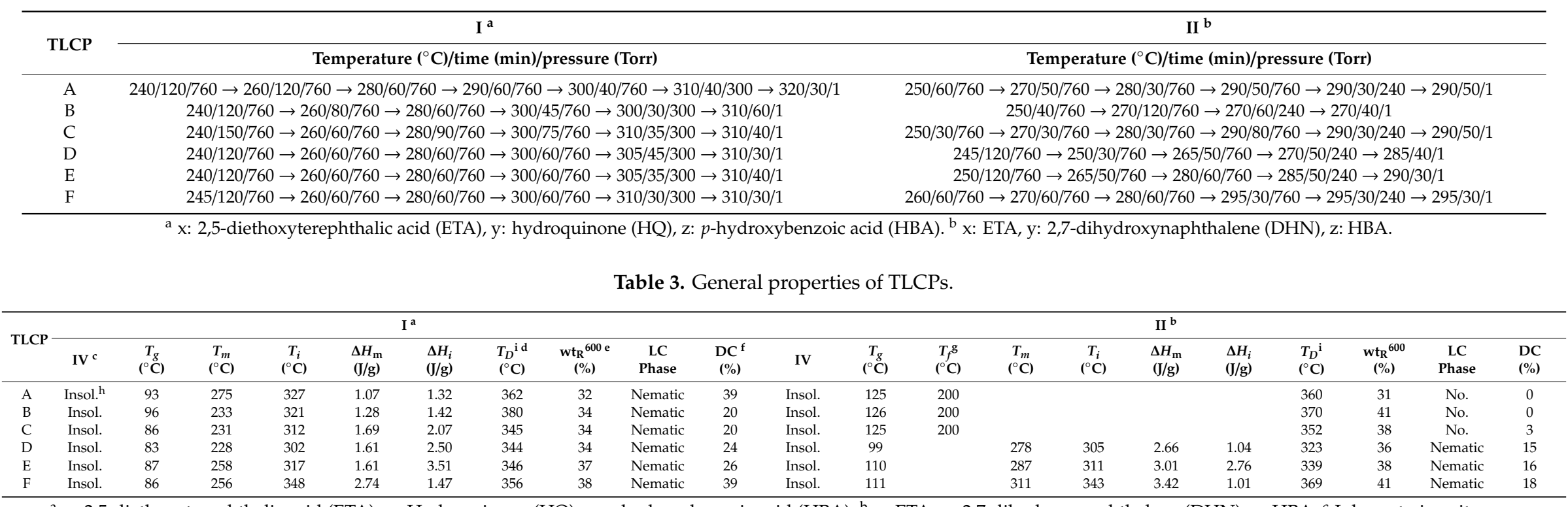

${ }^{\mathrm{a}} \mathrm{x}$ : 2,5-diethoxyterephthalic acid (ETA), y: Hydroquinone (HQ), z: $p$-hydroxybenzoic acid (HBA). ${ }^{\mathrm{b}} \mathrm{x}:$ ETA, y: 2,7-dihydroxynaphthalene (DHN), z: HBA. ${ }^{\mathrm{c}}$ Inherent viscosity was measured at a concentration of $0.1 \mathrm{~g} / \mathrm{dL}$ solution in phenol/p-chlorophenol/TCE $=25 / 40 / 35(\mathrm{w} / \mathrm{w} / \mathrm{w})$ at $25{ }^{\circ} \mathrm{C} .{ }^{\mathrm{d}}$ At $2 \%$ initial weight-loss temperature. ${ }^{\mathrm{e}}$ Weight percent of residue at $600{ }^{\circ} \mathrm{C}$. ${ }^{\mathrm{f}}$ Degree of crystallinity. ${ }^{\mathrm{g}}$ Flow temperature is observed by polarized optical micrographs. ${ }^{\mathrm{h}}$ Insoluble. 


\section{Results and Discussion}

\subsection{Thermal Behavior}

The results of the $2^{\text {nd }}$ heating were used to obtain thermal properties $\left(T_{g}, T_{m}\right.$, and $\left.T_{i}\right)$ using DSC, and the scanning temperature ranges were determined in advance using TGA to prevent thermal decomposition during scanning. The thermal properties of the two TLCP series are summarized in Table 3. The $T_{g}$, which is known to depend on the flexibility and rigidity of the monomers, reflects changes in chain interactions and the free volume. In other words, the $T_{g}$ is influenced by the segmental motion of the chains and by the substituent size [27]. If the monomer in the main chain has a rigid structure and a large substituent, the free volume will be large, and the $T_{g}$ value will be high. In the TLCP-I series, the copolymers were synthesized by varying the HBA molar ratio between 0 and 5 . The $T_{g}$ value of the polymer without the HBA was $93^{\circ} \mathrm{C}$, but this value increased to $96{ }^{\circ} \mathrm{C}$ when $1 \mathrm{~mol}$ of HBA was added. Increasing the HBA amount further to 3 mol decreased the $T_{g}$ value to $83^{\circ} \mathrm{C}$ (sample I-D), but the $T_{g}$ value then increases to $87^{\circ} \mathrm{C}$ when 4 mol of HBA was used. Finally, with 5 mol of $\mathrm{HBA}$, the copolymer maintained a $T_{g}$ value of $86^{\circ} \mathrm{C}$.

The $T_{g}$ values of the TLCP-II series showed a similar trend. When $3 \mathrm{~mol}$ of HBA was used (sample II-D), the $T_{g}$ value was the lowest $\left(99^{\circ} \mathrm{C}\right)$, whereas, at $4 \mathrm{~mol}$, the $T_{g}$ value increased to $110^{\circ} \mathrm{C}$ (sample II-E), which was similar to that obtained with 5 mol of $\mathrm{HBA}\left(111^{\circ} \mathrm{C}\right)$. At low ratios of HBA in the random copolymer, the molecular structure was disturbed, resulting in easier chain movement and increased mobility, and consequently, a lower $T_{g}$. This phenomenon can be explained thermodynamically using the following equation:

$$
T=\Delta H / \Delta S
$$

where $\Delta H$ is the enthalpy change and $\Delta S$ the entropy change.

However, when the ratio of HBA increases, a block copolymer (poly(hydroxy benzoate) (PHB)) of HBA itself was formed, and the $T_{g}$ increased. Generally, a block copolymer has a large $\Delta H$ and a relatively small $\Delta S$, resulting in an enhancement of the thermal properties, such as an increase of $T_{g}[28,29]$. This phenomenon was observed to be consistent for both series of synthesized TLCPs. The $\mathrm{T}_{g}$ values for the TLCP-II series ranged from 99 to $126^{\circ} \mathrm{C}$, depending on the HBA molar ratio.

The $T_{g}$ values of the copolymers containing DHN (TLCP-II series) were higher than those of the polymers containing HQ (TLCP-I series). Compared with the HQ monomer, the naphthalene monomer was substituted with nonlinear units at the 2 and 7 positions. There is a large volume of DHN; therefore, the free volume is large, resulting in higher $T_{g}$ values for copolymers with DHN than for those with HQ in all HBA molar ranges [19,30]. In other words, the bulky DHN monomer made the movement of the polymer chain difficult, limiting segmental motion, so that the $T_{g}$ of naphthalene increases more than that of $\mathrm{HQ}$.

The $T_{m}$ values of the TLCP-I series, which includes HQ, showed a similar tendency to the $T_{g}$ values (Table 3). The polymer without HBA showed a melting point of $275^{\circ} \mathrm{C}$. However, as the HBA molar ratio in the copolymer increased from 1 to 3 , the $T_{m}$ value decreased from 233 to $228^{\circ} \mathrm{C}$. As the HBA ratio increased, $\Delta S$ increased, resulting in a decrease in $T_{m}\left(228^{\circ} \mathrm{C}\right)$. Above $4 \mathrm{~mol} \mathrm{HBA}$, the $T_{m}$ values were in the range of $256-258^{\circ} \mathrm{C}$, as an excess of HBA monomers, resulted in the formation of a block copolymer of HBA, thus increasing the $T_{m}$ [31]. In the case of the TLCP-II series containing DHN monomers, the copolymer was amorphous, and the $T_{m}$ was not observed up to an HBA molar ratio of 2 owing to the flexible dialkoxy groups in ETA and the kinked structure of DHN [32]. The flow temperature observed by polarized optical microscopy was approximately $200{ }^{\circ} \mathrm{C}$, regardless of the molar ratio of HBA. However, when the HBA ratio was $\geq 3, T_{m}$ values were observed. On increasing the HBA ratio from 3 to 5 , the $T_{m}$ values gradually increased from 278 to $311{ }^{\circ} \mathrm{C}$. The DSC results for the two TLCP series are shown in Figure 2. 
I

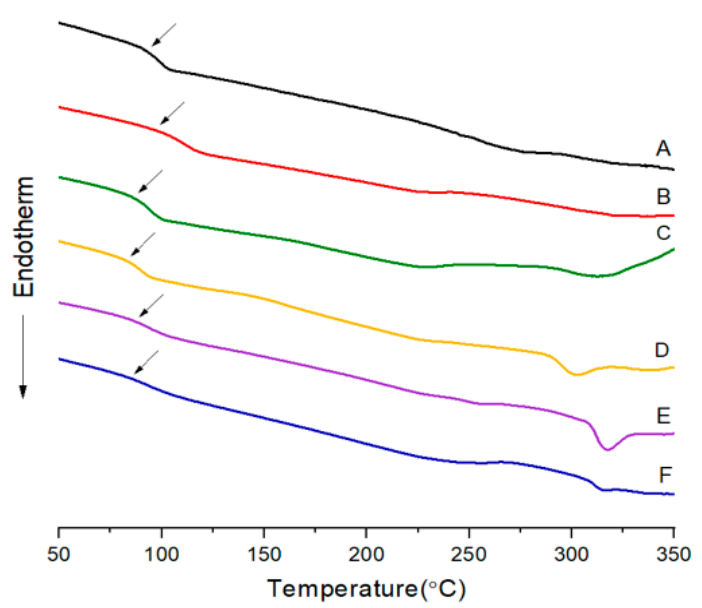

II

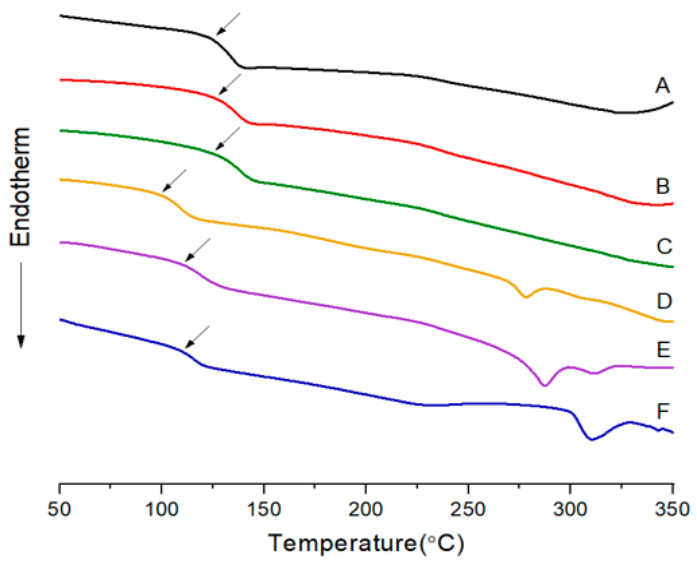

Figure 2. DSC thermograms of TLCP-I and TLCP-II series.

The same tendency was observed for the $T_{i}$ values as for the $T_{g}$ and $T_{m}$ values (Table 3 ). In the case of the TLCP-I series, the polymer without HBA had a $T_{i}$ value of $327^{\circ} \mathrm{C}$, but the $T_{i}$ values of the copolymers with 1-3 mol of HBA monomer content gradually decreased from 321 to $302^{\circ} \mathrm{C}$. However, when the ratio of HBA in the copolymer increased from 3 to 5 , the $T_{i}$ value increased from 302 to $348^{\circ} \mathrm{C}$. In the case of the TLCP-II series, $T_{i}$ is not observed up to 2 mol of HBA (sample II-C), similar to the behavior observed for $T_{m}$. The kinked structure of DHN and the dialkoxy substituents of ETA do not promote liquid crystallinity. In contrast, the simple and linear structure of HBA helps to form liquid crystalline mesophases. Hence, when the molar ratio of HBA increased from 3 to 5 , the $T_{i}$ value increased from 305 to $343^{\circ} \mathrm{C}$. These values were similar to those of TLCP-I (302-348 $\left.{ }^{\circ} \mathrm{C}\right)$. This phenomenon can also be explained by the rigidity of the HBA monomer in part of the main chain.

The enthalpy changes of the crystal-anisotropic transition $\left(\Delta H_{m}\right)$ and the enthalpy change of the anisotropic-isotropic transition $\left(\Delta H_{i}\right)$ were very small, as shown in Table 3, and no constant tendency was found. For example, in the case of TLCP-I, as the number of moles of HBA increased from 0 to 5 moles, $\Delta H_{m}$ were $1.07-2.74 \mathrm{~J} / \mathrm{g}$, and $\Delta H_{i}$ were $1.32-3.51 \mathrm{~J} / \mathrm{g}$, respectively. In the case of TLCP-II, when the number of moles of HBA increased from 3 to 5 moles, the values of $\Delta H_{m}$ were 2.66-3.42 J/g and $\Delta H_{i}$ was $1.01-2.76 \mathrm{~J} / \mathrm{g}$. This result is because the HBA monomer has a random sequence in the melt polymerization process, and the alkoxy side group present in the main chain reduces the effect of enthalpy.

The TGA results for the two TLCP series are shown in Figure 3 and summarized in Table 3. First, in the case of the TLCP-I series, the tendency observed with varying the HBA ratio is similar to the thermal property results $\left(T_{g}, T_{m}\right.$, and $\left.T_{i}\right)$, as described above. A $T_{D}{ }^{i}$ value of $362{ }^{\circ} \mathrm{C}$ was observed for HBA $=0$ mole (sample I-A), but this value decreased gradually from 380 to $344^{\circ} \mathrm{C}$ when HBA was increased from 1 to $3 \mathrm{~mol}$. When HBA was further increased to $5 \mathrm{~mol}$, the $T_{D}{ }^{i}$ value increased 
again to $356^{\circ} \mathrm{C}$. Similar results were observed for the TLCP-II series, with various changes in $T_{D}{ }^{i}$ depending on the HBA ratio. Therefore, to control the deformation owing to thermal decomposition during processing from the melted state, the structure and ratio of the monomers in the copolymer should be carefully selected. The overall $T_{D}{ }^{i}$ results for both series were generally similar. However, higher $w t_{R}{ }^{600}$ values were observed for the TLCP-II series with DHN monomers than for the TLCP-I series with HQ monomers. This difference is because more charcoal is produced at high temperatures from naphthalene derivatives, which contain two benzene rings, than from $\mathrm{HQ}$, which contains one benzene ring. Overall, the reason why the value of $w t_{R}{ }^{600}$ is generally lower than that of the rigid rod-like main chain TLCP is explained by the alkoxy side group in the main chain.

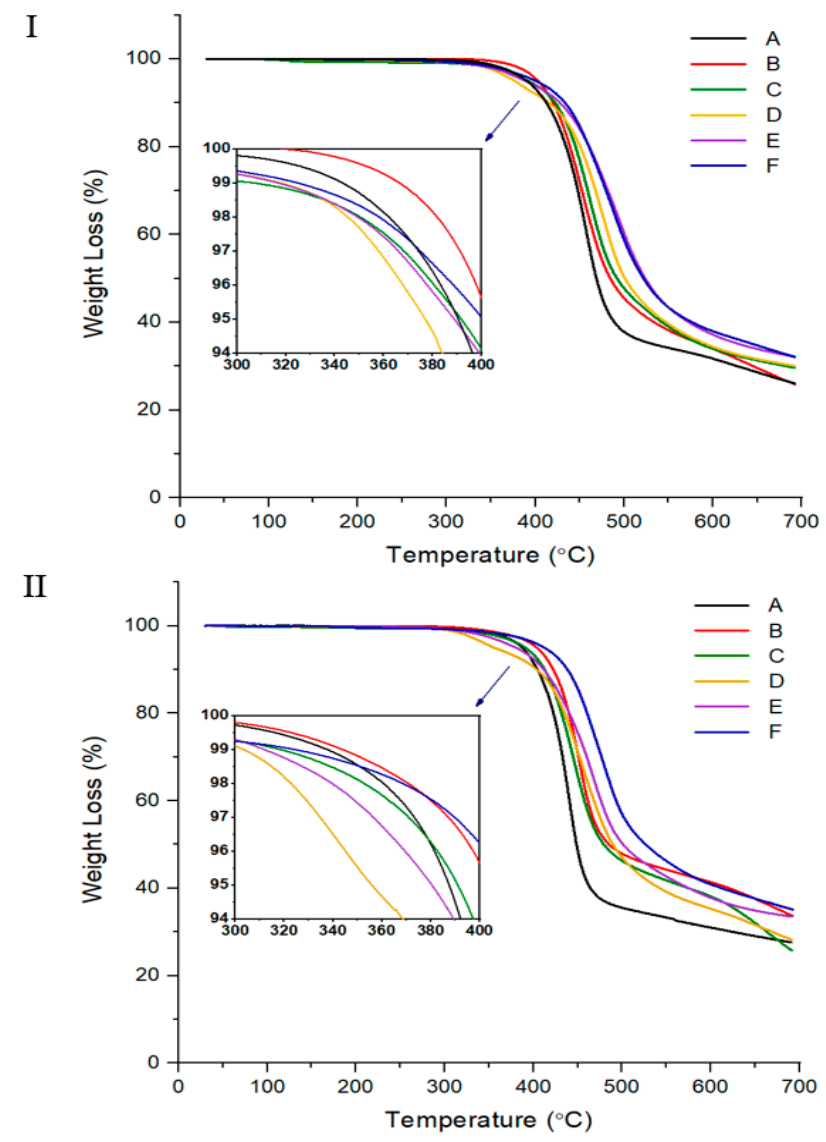

Figure 3. TGA thermograms of TLCP-I and TLCP-II series.

For the two TLCP series, the changes in the overall thermal properties $\left(T_{g}, T_{m}, T_{i}\right.$, and $\left.T_{D}{ }^{i}\right)$ with the molar ratio of HBA are compared in Figure 4. In each series, the minimum values were obtained when 3 mol of HBA was added to the copolymer. These values then gradually increased as the HBA molar ratio increased up to 5 . The shape of the eutectic curve, which depends on the amount of HBA monomer content in the TLCP copolymer, has been described in detail previously, and similar results have been published by several researchers $[11,19,32,33]$. The temperature change of our study according to the HBA molar ratio is small compared to other research results, which is probably due to the alkoxy side groups in the main chain.

We found that the TLCP copolymer series containing DHN and HQ can be melt-processed without thermal decomposition problems by controlling the ratio of HBA monomer. It was also found that controlling the HBA molar ratio can determine the thermal properties of the TLCP copolymer. 
I

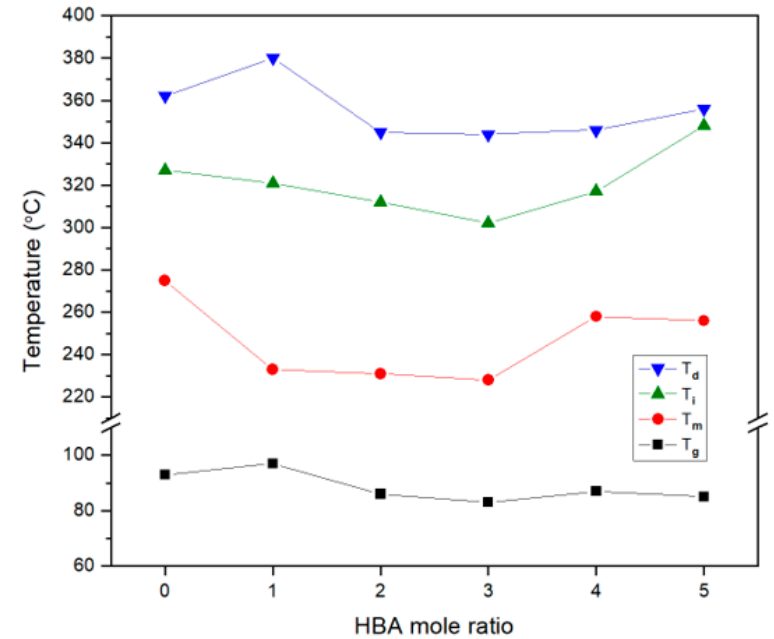

II

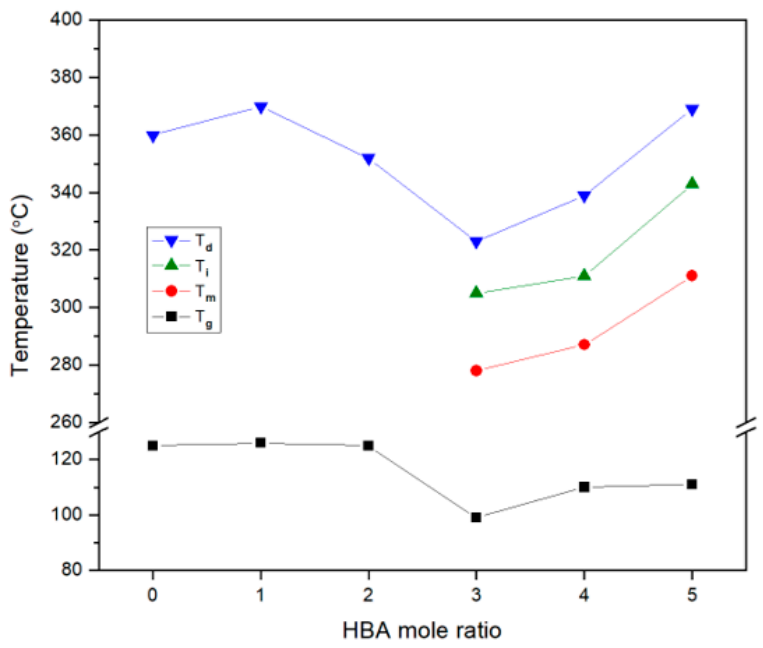

Figure 4. Thermal properties of TLCP-I and TLCP-II series with various HBA ratios.

\subsection{Liquid Crystalline Mesophase}

Liquid crystallinity, which occurs between $T_{m}$ and $T_{i}$, can be observed using an optical polarizing microscope $[34,35]$. Figure 5 shows the liquid crystallinity observed for polymers in the TLCP-I and TLCP-II series at various temperatures. A numer heating and cooling processes were taken to get a better picture, and these LC mesophases were obtained by the heating process between $T_{m}$ and $T_{i}$. All the liquid crystalline mesophases show a thread-like nematic texture [36]. The nematic phases show poorly developed texture, which is mainly due to a high molecular weight or poor flow of the substance above the $T_{m}$.

The stability of the mesophase of an LCP depends on the stiffness and aspect ratio of the mesogenic unit. If the mesogens in the main chain of the polymer are straight and rigid rods, the mesophase of the LCP can be stabilized. Thus, the HBA monomers can stabilize the liquid crystalline phase, regardless of the HBA ratio in the copolymer. However, as in the TLCP-II series, if a 2,7-substituted kinked monomer (DHN) is included in the main chain, the liquid crystalline mesophase is destroyed, and a liquid crystal texture is not observed [37]. As mentioned in the description of $T_{m}$ and $T_{i}$, liquid crystal textures are not observed when the HBA molar ratio is between 0 and 2 in the TLCP-II series. 
I

(a)

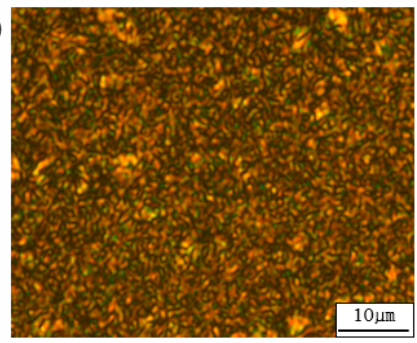

(b)

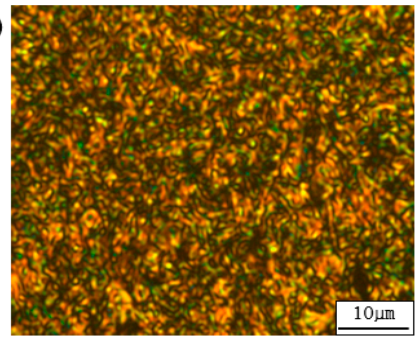

(c)

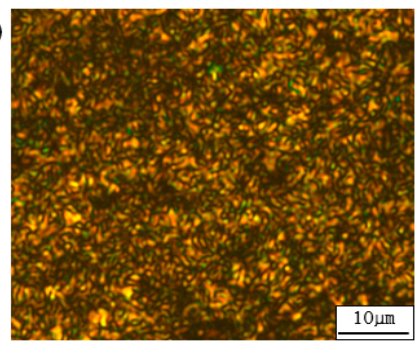

II

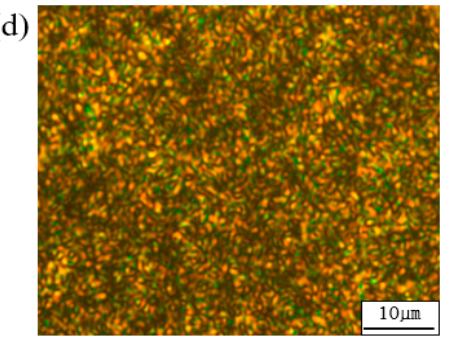

(e)

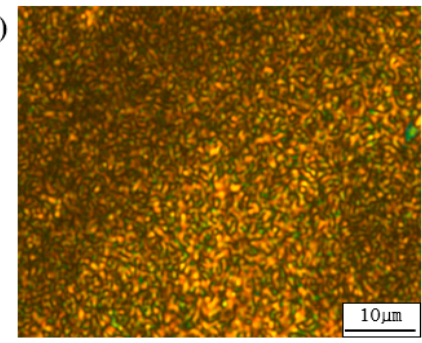

(f)

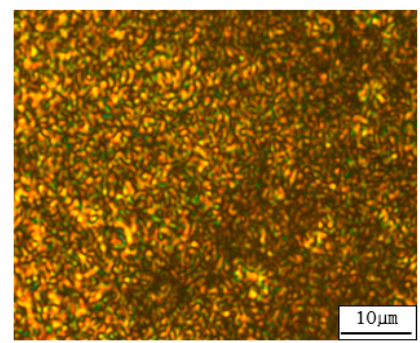

Figure 5. Polarized optical micrographs of (a) I-D at $280{ }^{\circ} \mathrm{C}$, (b) I-E at $300{ }^{\circ} \mathrm{C}$, (c) I-F at $270{ }^{\circ} \mathrm{C}$, (d) II-D at $280{ }^{\circ} \mathrm{C}$, (e) II-E at $295^{\circ} \mathrm{C}$, and (f) II-F at $315^{\circ} \mathrm{C}$ (magnification $200 \times$ ).

\section{3. $X R D$}

The wide-angle XRD patterns of the two TLCP series are shown in Figure 6. Although their diffractograms are different from each other, the XRD patterns of the TLCPs as a whole are not largely different from general crystal characteristics. For the copolymers, major peaks are observed between $2 \theta=20^{\circ}$ and $30^{\circ}$, indicating a semicrystalline character. The degree of crystallinity (DC) was calculated from Ic, which is the peak area of the crystalline region, and I $a$, which is the peak area of the amorphous region, as follows [38]:

$$
\mathrm{DC}(\%)=[I c /(I c+I a)] \times 100
$$

The calculated DC values are summarized in Table 3. In the TLCP-I series, the polymer composed of only ETA and HQ had a DC of 39\%, whereas the DC of the copolymer with 1 mol of HBA (sample I-B) abruptly decreased to $20 \%$. However, as the molar ratio of HBA in the copolymer increased to 5, DC gradually increased to $39 \%$. As previously mentioned, short and rigid HBAs contribute to the crystallinity of the entire copolymer. Thus, an increase in DC will occur at higher HBA ratios. In contrast, in the TLCP-II series, an amorphous diffraction pattern was observed at an HBA ratio of 1 owing to ETA having flexible alkyl groups and DHN having a kinked structure. However, at an HBA molar ratio of 2 (sample II-C), a very small crystalline peak was observed. When the HBA ratio was increased to 5, the intensity of the peak increased further. As shown in Table 3, when the ratio of HBA in the copolymer increases from 2 to 5 , the DC increases from $3 \%$ to $18 \%$. Comparing the two TLCP series, it was found that the linear structure of the HQ monomer had a greater effect on the crystallization of the LCP main chain than the kinked structure of the DHN monomer. Based on the results in Figure 6, the $d$ and $2 \theta$ values of each XRD peak are summarized in Table 4 [39]. 


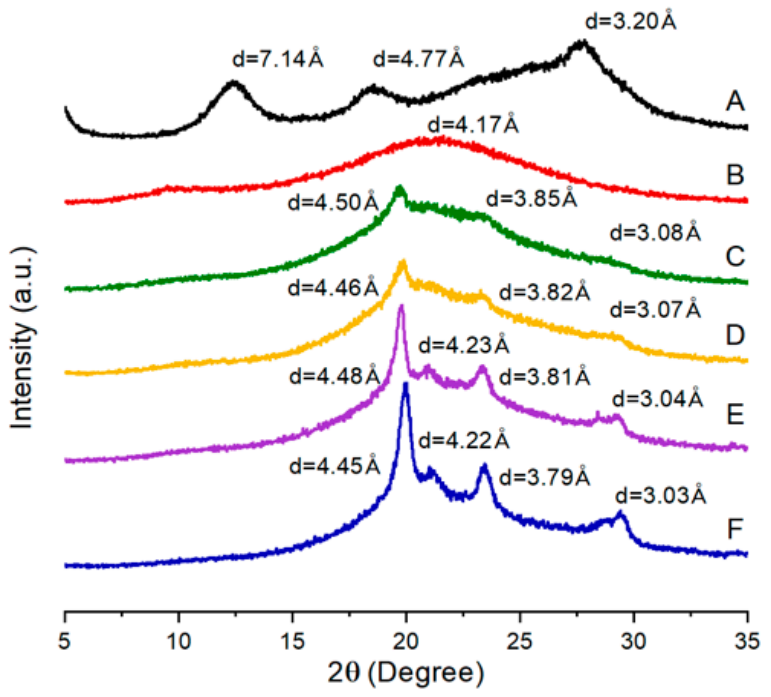

II

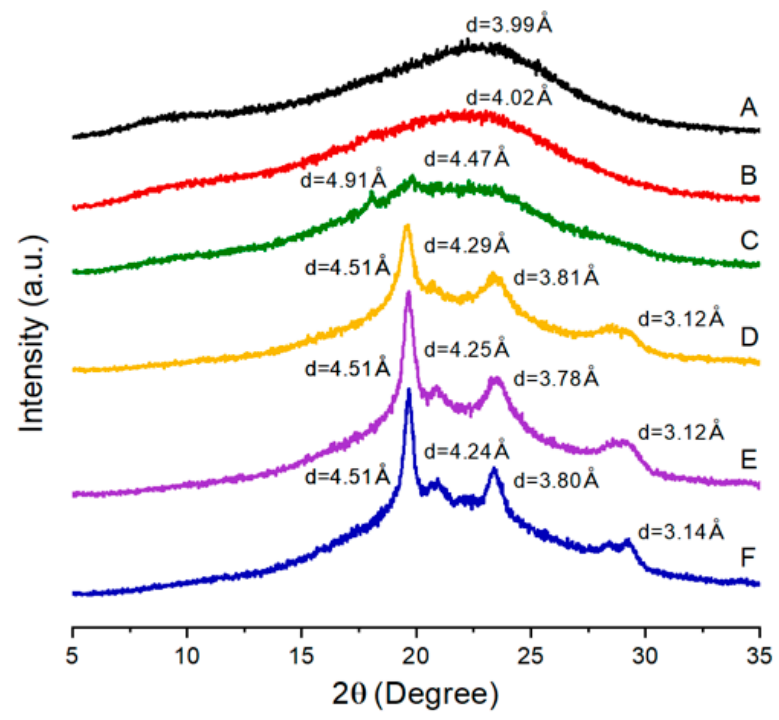

Figure 6. XRD patterns of TLCP-I and TLCP-II series.

Table 4. $d$ values corresponding to the XRD peaks of the TLCPs.

\begin{tabular}{|c|c|c|c|c|c|c|c|c|}
\hline \multirow{3}{*}{$\begin{array}{c}\text { TLCP } \\
\mathrm{A}\end{array}$} & \multicolumn{8}{|c|}{$d(\AA ̊ \AA)(2 \theta$ (degree) $)$} \\
\hline & \multicolumn{4}{|c|}{$I^{a}$} & \multicolumn{4}{|c|}{ II $^{\mathbf{b}}$} \\
\hline & $7.14(12.38)^{c}$ & 4.77 (18.56) & $3.20(27.82)$ & - & $3.99(22.24)$ & - & - & - \\
\hline B & $4.17(21.28)$ & - & - & - & $4.02(22.1)$ & - & - & - \\
\hline $\mathrm{C}$ & $4.50(19.72)$ & $3.85(23.08)$ & $3.08(28.96)$ & - & $4.91(18.04)$ & 4.47 (19.84) & - & - \\
\hline D & $4.46(19.88)$ & $3.82(23.26)$ & $3.07(29.06)$ & - & $4.51(19.64)$ & $4.29(20.7)$ & $3.81(23.34)$ & $3.12(28.56)$ \\
\hline $\mathrm{E}$ & $4.48(19.78)$ & $4.23(20.96)$ & $3.81(23.32)$ & $3.04(29.3)$ & $4.51(19.68)$ & $4.25(20.88)$ & $3.78(23.52)$ & $3.12(28.58)$ \\
\hline F & $4.45(19.94)$ & $4.22(21.02)$ & 3.79 (23.44) & $3.03(29.4)$ & $4.51(19.68)$ & $4.24(20.94)$ & $3.80(23.4)$ & $3.14(28.42)$ \\
\hline
\end{tabular}

XRD peaks were investigated between $T_{m}$ and $T_{i}$ ranges showing LC mesophase, and the results are shown in Figure 7. As expected, the XRD obtained at $285^{\circ} \mathrm{C}$ was nearly amorphous, and the sharp peaks were almost absent compared to the results obtained at $25^{\circ} \mathrm{C}$. In high-temperature conditions, structural irregularity caused by a random sequence of monomer units, together with the random existence of alkoxy side group or kinked structures, certainly would hinder crystallization. 
I

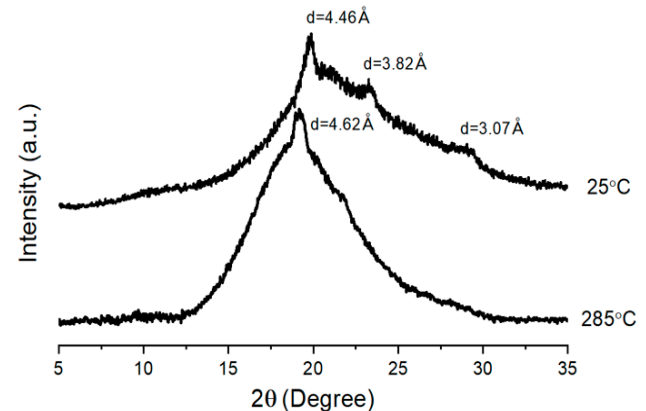

II

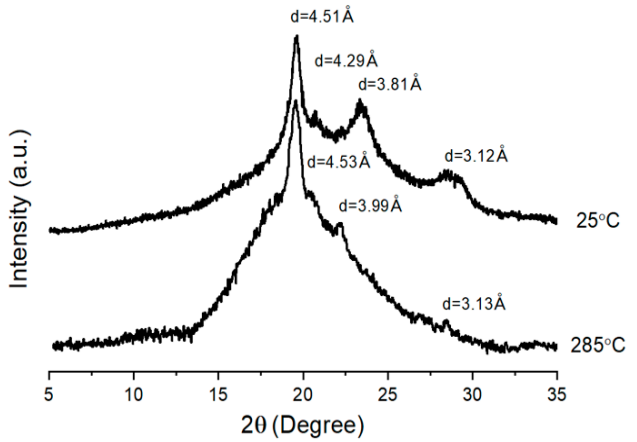

Figure 7. Patterns of sample D in two TLCP series at $25^{\circ} \mathrm{C}$ and $285^{\circ} \mathrm{C}$.

Figure 8 shows a 3-D computer simulation illustrating the detailed relationship between the copolymer structure and crystallinity. The chemical structures of copolymers in the two series obtained using the same molar ratios of HBA ( 1 and 5 mol HBA) are compared. In the TLCP-I series, the copolymer obtained using $5 \mathrm{~mol}$ of HBA (sample I-F) shows a more linear structure than that obtained using $1 \mathrm{~mol}$ of HBA (sample I-B). This result is due to the effect of the rigid rod-shaped HBA monomer on the crystallinity.

I (B)

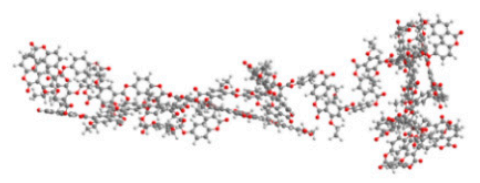

(F)

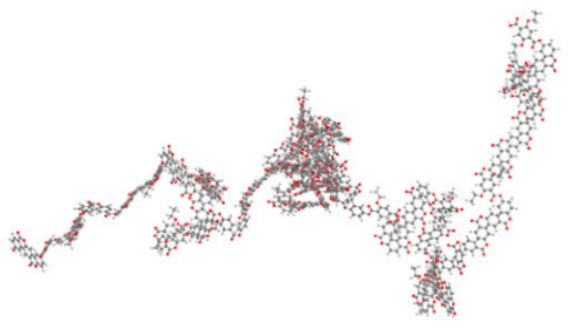

II (B)

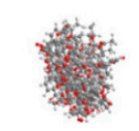

(F)

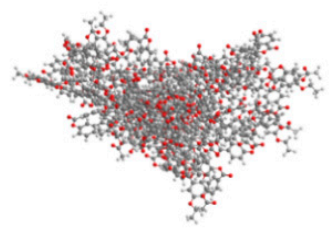

Figure 8. Comparison of the 3-D chemical structures of samples B and F in two TLCP series. 
Similar results were obtained for the TLCP-II series, as the copolymer containing 5 mol of HBA shows a more linear structure than that containing 1 mol of HBA (sample II-B), which is expected to affect the crystallinity. In contrast, when comparing the 3-D structures of the two TLCP series at the same HBA ratio, the TLCP-I structure is more linear compared to the TLCP-II structure, but the structure of the TLCP-II is more spherical. Thus, it was found that the copolymer structures directly affect the crystallinity.

\section{4. ${ }^{13} \mathrm{C}$ Chemical Shifts and Relaxation Times}

Structural analysis of the TLCP-I and TLCP-II series was carried out by solid-state ${ }^{13} \mathrm{C} \mathrm{CP} / \mathrm{MAS}$ NMR. The ${ }^{13} \mathrm{C}$ chemical shifts of the TLCP-I and -II series were obtained for the carbons of the alkoxy groups and aromatic rings at room temperature. In the TLCP-I series, for sample I-A, the ${ }^{13} \mathrm{C}$ chemical shifts for $\mathrm{CH}_{3}$ and $\mathrm{CH}_{2}$ of the alkoxy group are observed at 14.79 and $64.69 \mathrm{ppm}$, respectively, as shown in Figure 9. The peaks at 115.96, 122.64, 148.87, and $151.63 \mathrm{ppm}$ are assigned to the benzene rings in ETA and $\mathrm{HQ}$, and the chemical shift for $\mathrm{C}=\mathrm{O}$ is observed at $164.78 \mathrm{ppm}[40,41]$. The peak for the carbon of $\mathrm{C}=\mathrm{O}$ bonds has a relatively low intensity. The spinning sidebands for the benzene rings in ETA and HQ are marked with asterisks in Figure 9. The chemical shifts of all carbons are consistent with the chemical structure shown in Figure 9. In the case of sample I-F (Figure 10), the ${ }^{13} \mathrm{C}$ chemical shifts for the alkoxy group, ETA, HQ, and $\mathrm{C}=\mathrm{O}$ are similar to those observed in I-A. The ${ }^{13} \mathrm{C}$ chemical shifts for the benzene ring in PHB are located at 126.37, 132.34, and $148.70 \mathrm{ppm}$.

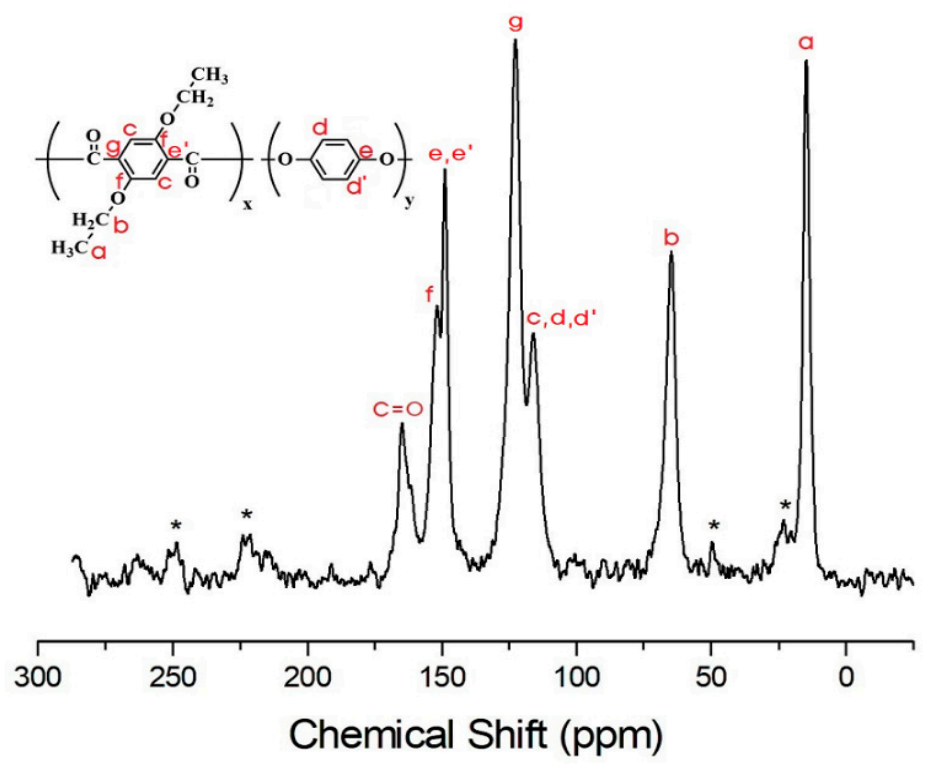

Figure 9. ${ }^{13} \mathrm{C}-\mathrm{NMR}$ chemical shifts of sample I-A at room temperature. In the chemical formula, $\mathrm{x}: \mathrm{y}=1: 1$. The spinning sidebands are marked with asterisks.

By contrast, in the TLCP-II series, for sample II-A, the ${ }^{13} \mathrm{C}$ chemical shifts of $\mathrm{CH}_{3}$ and $\mathrm{CH}_{2}$ are observed at 14.36 and $64.60 \mathrm{ppm}$, respectively (Figure 11). The ${ }^{13} \mathrm{C}$ peak at $164.11 \mathrm{ppm}$ corresponds to $\mathrm{C}=\mathrm{O}$, and the signals at $149.53,133.98,128.91$, and $119.19 \mathrm{ppm}$ are attributed to the aromatic rings in ETA and DHN [42]. The asterisks in Figure 11 represent the spinning sidebands of ETA and DHN rings. The ${ }^{13} \mathrm{C}$ chemical shifts for the alkoxy group, $\mathrm{C}=\mathrm{O}$, and the aromatic rings in ETA, DHN, and PHB in sample II-F are consistent with the chemical structure shown in Figure 12. The results for II-F are similar to those for samples II-B, II-C, II-D, and II-E. 


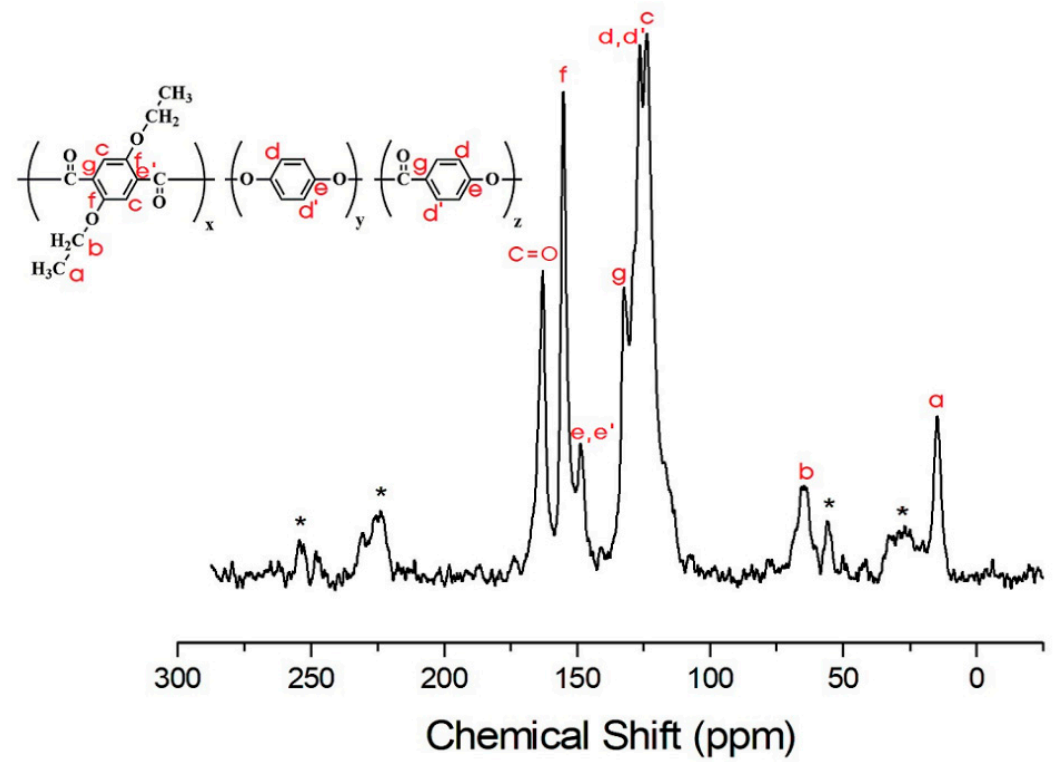

Figure 10. ${ }^{13} \mathrm{C}-\mathrm{NMR}$ chemical shifts of sample I-F at room temperature. In the chemical formula, $x: y: z=1: 1: 5$. The spinning sidebands are marked with asterisks.

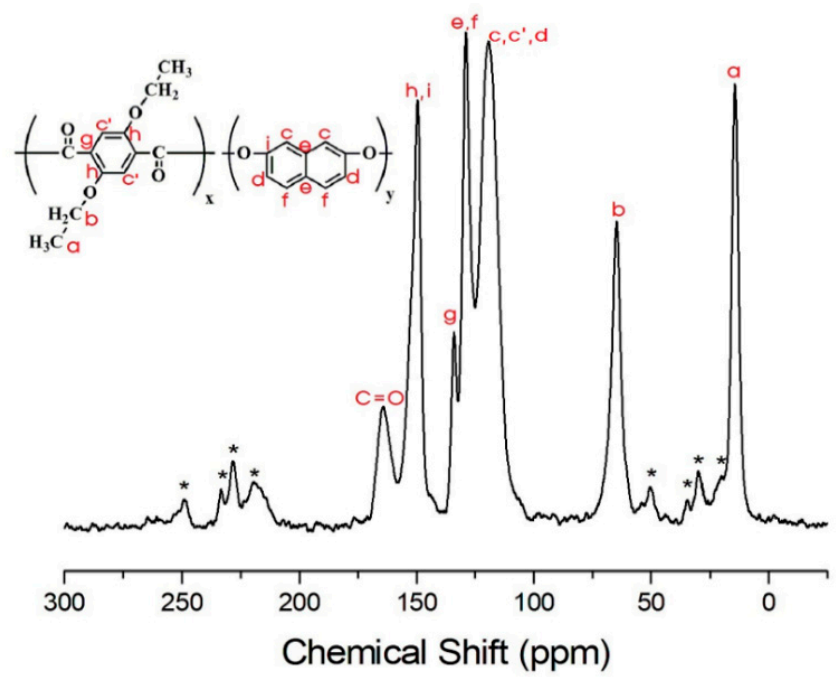

Figure 11. ${ }^{13} \mathrm{C}-\mathrm{NMR}$ chemical shifts of sample II-A at room temperature. In the chemical formula, $\mathrm{x}: \mathrm{y}=1: 1$. The spinning sidebands are marked with asterisks.

To obtain the ${ }^{13} \mathrm{C}-\mathrm{NMR} T_{1 \rho}$ values, the magnetization recovery curves for the TLCP-I and II series were measured as a function of the delay time. All the magnetization recovery traces can be described by a single-exponential function [43]:

$$
I(t)=I_{0} \exp (-W t)
$$

where $I(t)$ is the magnetization according to the spin-locking pulse duration $t$, and $I_{0}$ is the total nuclear magnetization at thermal equilibrium. The $T_{1 \rho}(=1 / W)$ values were obtained from the slopes of the delay time vs. intensity curves, and the results for each carbon in the TLCP-I and -II series are listed in Tables 5 and 6 . The ${ }^{13} \mathrm{C}$ relaxation times in the TLCP-I and -II series are compared according to the molar ratio of HBA. The ${ }^{13} \mathrm{C}-\mathrm{NMR} \mathrm{T}_{1}$ values for the $\mathrm{CH}_{3}$ and $\mathrm{CH}_{2}$ of sample I-A are 39.2 and $4.4 \mathrm{~ms}$, respectively (Table 5). The $\mathrm{CH}_{3}$ group has a longer relaxation time than the $\mathrm{CH}_{2}$ of the alkoxy groups, which is consistent with the fact that dipolar relaxation is more efficient based on the number of bonded protons. In addition, the carbonyl carbons $(\mathrm{C}=\mathrm{O})$ have greater $T_{1 \rho}$ values than the carbons 
of the alkoxy group. When the molar ratio of HBA is increased, the ${ }^{13} \mathrm{C}-\mathrm{NMR} T_{1 \rho}$ values for the alkoxy group, $\mathrm{C}=\mathrm{O}$, and the aromatic rings in TPA, HQ, and HBA decrease, as shown in Table 5.

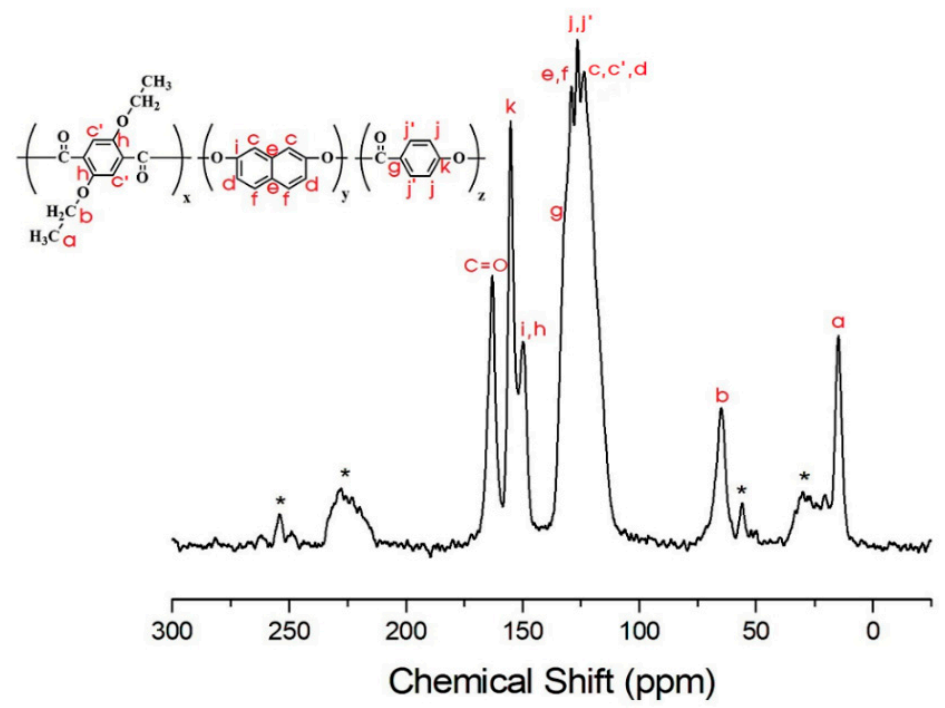

Figure 12. ${ }^{13} \mathrm{C}-\mathrm{NMR}$ chemical shifts of sample II-F at room temperature. In the chemical formula, $\mathrm{x}: \mathrm{y}: \mathrm{z}=1: 1: 5$. The spinning sidebands are marked with asterisks.

Table 5. Spin-lattice relaxation time $T_{1 \rho}(\mathrm{ms})$ in the rotating frame for each carbon in the TLCP-I series at room temperature.

\begin{tabular}{ccccccc}
\hline TLCP & I-A & I-B & I-C & I-D & I-E & I-F \\
\hline $\mathrm{CH}_{3}-\mathrm{a}$ & 39.2 & 39.7 & 23.8 & 24.4 & 25.4 & 25.7 \\
$\mathrm{CH}_{2}-\mathrm{b}$ & 4.4 & 3.5 & 4.1 & 3.4 & 5.1 & 2.9 \\
$\mathrm{c}$ & 12.2 & 17.4 & 11.9 & 14.7 & 14.1 & 14.0 \\
$\mathrm{~d}$ & 41.9 & 46.0 & 42.9 & 42.9 & 47.3 & 45.2 \\
$\mathrm{e}$ & 125.9 & 95.9 & 90.8 & 80.4 & 72.9 & 66.6 \\
$\mathrm{f}$ & 121.0 & 81.5 & 83.1 & 70.4 & 77.8 & 87.8 \\
$\mathrm{~g}$ & 12.2 & 8.4 & 6.7 & 6.1 & 5.8 & 6.7 \\
$\mathrm{C}=\mathrm{O}$ & 92.0 & 62.2 & 56.0 & 59.1 & 65.8 & 65.8 \\
\hline
\end{tabular}

Table 6. Spin-lattice relaxation time $T_{1 \rho}(\mathrm{ms})$ in the rotating frame for each carbon in the TLCP-II series at room temperature.

\begin{tabular}{ccccccc}
\hline TLCP & II-A & II-B & II-C & II-D & II-E & II-F \\
\hline $\mathrm{CH}_{3}$-a & 55.1 & 42.5 & 38.5 & 34.0 & 24.5 & 36.6 \\
$\mathrm{CH}_{2}$-b & 8.2 & 5.8 & 5.8 & 6.4 & 4.5 & 6.7 \\
$\mathrm{c}, \mathrm{d}$ & 29.3 & 21.2 & 18.0 & 19.0 & 18.0 & 27.4 \\
$\mathrm{e}, \mathrm{f}$ & 68.9 & 53.1 & 42.7 & 23.9 & 22.3 & 20.5 \\
$\mathrm{~g}$ & 119.9 & 118.0 & & & & \\
$\mathrm{~h}, \mathrm{i}$ & 191.7 & 144.1 & 136.5 & 130.1 & 106.5 & 108.1 \\
$\mathrm{j}$ & & & & 80.5 & 75.2 & \\
$\mathrm{k}$ & & & 107.8 & 114.2 & 101.1 & 94.6 \\
$\mathrm{C}=\mathrm{O}$ & 182.6 & 101.1 & 100.4 & 102.3 & 83.1 & 77.6 \\
\hline
\end{tabular}

The ${ }^{13} \mathrm{C}-\mathrm{NMR} T_{1 \rho}$ values for the TLCP-II series are shown in Table 6. Here, the ${ }^{13} \mathrm{C}$ peak for the benzene ring in HBA somewhat overlaps the peak for the aromatic rings of ETA and HQ, as shown in Figure 12, making it difficult to obtain the $T_{1 \rho}$ values. For $\mathrm{C}=\mathrm{O}$ in sample II-A, the $T_{1 \rho}$ value is remarkably high. Thus, the alkoxy group and $\mathrm{C}=\mathrm{O}$ in the TLCP-II series have higher mobilities than those in the TLCP-I series. Carbons e and $\mathrm{f}$ in sample I-A and carbons $\mathrm{g}, \mathrm{h}$, and $\mathrm{i}$ in sample II-A have longer relaxation times than the other carbons, as shown in Tables 5 and 6 . These greater $T_{1 \rho}$ values 
indicate a higher rigidity of the main chains, which implies that there are strong interfacial interactions between the aromatic rings and the polymer main chains and between the alkoxy groups and polymer main chains. The $T_{1 \rho}$ values for the TLCP-I and -II series indicate the effect of the HBA molar ratio on the mobility. All of the $\mathrm{C}$ atoms in the TLCP-II series have higher mobilities than those in the TLCP-I series.

\section{Conclusions}

Copolymers in the TLCP-I series included ETA, HQ, and HBA, whereas those in the TLCP-II series included ETA, DHN, and HBA. Both series were synthesized with varying molar ratios between HBA and the other two monomers (0-5). The thermal properties, liquid crystalline mesophases, and degrees of crystallinity of the polymers in the two TLCP series were investigated and compared. In both the TLCP series, the minimum $T_{g}, T_{m}, T_{i}$, and $T_{D}{ }^{i}$ values were observed at an HBA molar ratio of 3 . The liquid crystalline mesophases showed nematic schlieren textures in both series, but for the TLCP-II series, nematic textures were not observed at HBA ratios lower than 3 owing to the kinked DHN structure in the main chain. The degrees of crystallinity of the TLCP-I series containing the linear HQ monomer were higher than those of the TLCP-II series with the kinked DHN monomer.

The chemical structures of the polymers in the TLCP-I and TLCP-II series were confirmed based on the ${ }^{13} \mathrm{C}$ chemical shifts. From the $T_{1 \rho}$ values, the effects of the HBA molar ratio on carbon mobility were determined for the TLCP-I and -II series. The ${ }^{13} \mathrm{C}-\mathrm{NMR} T_{1 \rho}$ values decreased for all carbon atoms as the molar ratio of HBA monomers bound to the HQ, and DHN rings increased. In the TLCP-I series, the $T_{1 \rho}$ values decreased gradually with an increase in the HBA molar ratio, whereas in the TLCP-II series, the $T_{1 \rho}$ values decreased more sharply. This difference indicates that the polymers in the TLCP-II series are more rigid than those in the TLCP-I series and that the molar ratio of HBA has a greater influence on the TLCP-II series. Thus, the HBA rings in the TLCP-I series have higher mobility than those in the TLCP-II series. The ${ }^{13} \mathrm{C}-\mathrm{NMR} T_{1} \rho$ was dominated by fluctuations in the anisotropic chemical shifts and became shorter when the amplitude of the molecular motions decreased.

Author Contributions: J.-H.C. designed the project and wrote the manuscript. G.T.P. and W.J.L. prepared the samples and participated in the data analysis. A.R.L. performed NMR experiments. All authors reviewed the manuscript. All authors have read and agreed to the published version of the manuscript.

Funding: This research was supported by the Ministry of Trade, Industry \& Energy (MOTIE, Korea) under the Industrial Technology Innovation Program (No. 10063420, Development of high strengthen thermotropic liquid crystal polyester fiber). This research was supported by the Basic Science Research Program through the National Research Foundation of Korea (NRF), funded by the Ministry of Education (2018R1D1A1B07041593).

Conflicts of Interest: The authors declare no conflict of interest.

\section{References}

1. Schaller, R.; Peijs, T.; Tervoort, T.A. High-performance liquid-crystalline polymer films for monolithic "composites". Compos. Part A Appl. Sci. Manuf. 2016, 81, 296-304. [CrossRef]

2. Beers, D.E.; Ramirez, J.E. Vectran High-performance Fibre. J. Text. Inst. 2008, 81, 561-574. [CrossRef]

3. Kim, T.K.; Kim, S.O.; Chung, I.J. Synthesis and characterization of thermotropic liquid crystalline poly(ester imide)s. Polym. Adv. Technol. 1997, 8, 305-318. [CrossRef]

4. Chen, Y.; Wombacher, R.; Wendorff, J.H.; Visjager, J.; Smith, P.; Greiner, A. Design, synthesis, and properties of new biodegradable aromatic/aliphatic liquid crystalline copolyesters. Biomacromolecules 2003, 4, 974-980. [CrossRef]

5. Serbezeanu, D.; Vlad-Bubulac, T.; Hamciuc, C.; Aflori, M. Structure and properties of phosphorous-containing thermotropic liquid-crystalline aliphatic-aromatic copolyesters. Macromol. Chem. Phys. 2010, 211, 1460-1471. [CrossRef]

6. Lefèvre, J.; Feldman, K.; Giesbrecht, J.; Smith, P.; Tervoort, T.A.; Meijer, H.E.H. "Foil spintrusion" of high-performance polymer films. J. Polym. Sci. Part B Polym. Phys. 2012, 50, 1713-1727. [CrossRef]

7. Chae, H.G.; Kumar, S. Rigid-rod polymeric fibers. J. Appl. Polym. Sci. 2006, 100, 791-802. [CrossRef] 
8. Dingemans, T.; Knijnenberg, A.; Iqbal, M.; Weiser, E.; Stclair, T. All-aromatic liquid crystal thermosets: New high-performance materials for structural applications. Liq. Cryst. Today 2006, 15, 19-24. [CrossRef]

9. Pramoda, K.P.; Chung, T.S. Crystallization and melting behavior of zenite thermotropic liquid crystalline polymers. Polym. Eng. Sci. 2002, 42, 439-451. [CrossRef]

10. Pospiech, D.; Korwitz, A.; Eckstein, K.; Komber, H.; Jehnichen, D.; Suckow, M.; Lederer, A.; Arnhold, K.; Göbel, M.; Bremer, M.; et al. Fiber formation and properties of polyester/lignin blends. J. Appl. Polym. Sci. 2019, 136, 48257. [CrossRef]

11. Wang, X.; Bu, H.; Luise, R.R. Synthesis and eutectic behavior of liquid crystalline copolyesters. J. Polym. Sci. Part B Polym. Phys. 2009, 47, 2171-2177. [CrossRef]

12. Muhlebach, A.; Economy, J.; Johnson, R.D.; Karis, T.; Lyerla, J. Direct evidence for transesterification and randomization in a mixture of homopolyesters of poly(4-hydroxybenzoic acid) and poly(6-hydroxy-2-naphthoic acid) above 450 degree. Macromolecules 1990, 23, 1803-1809. [CrossRef]

13. Bhowmik, P.K.; Han, H.; Garay, R.O. Fully aromatic thermotropic liquid crystalline homopolyesters of 3,4'-benzophenone dicarboxylic acid. J. Polym. Sci. Part A Polym. Chem. 1994, 32, 333-342. [CrossRef]

14. Itoyama, K. Melt spinning of thermotropic liquid-crystal polyesters to form ultrahigh-modulus filaments. J. Polym. Sci. Part B Polym. Phys. 1988, 26, 1845-1863. [CrossRef]

15. Nelson, A.M.; Fahs, G.B.; Moore, R.B.; Long, T.E. High-performance segmented liquid crystalline copolyesters. Macromol. Chem. Phys. 2015, 216, 1754-1763. [CrossRef]

16. Wilsens, C.H.R.M.; Noordover, B.A.J.; Rastogi, S. Aromatic thermotropic polyesters based on 2,5-furandicarboxylic acid and vanillic acid. Polymer 2014, 55, 2432-2439. [CrossRef]

17. Hirano, H.; Kadota, J.; Agari, Y.; Harada, T.; Tanaka, M.; Hasegawa, K. Linear polymers with sulfur in the main chain. IV. Synthesis of thermotropic liquid-crystalline polythioesters based on 4,4'-biphenyldithiol with excellent adhesive properties. Polym. Eng. Sci. 2007, 47, 262-269. [CrossRef]

18. Young-Wan, K.; Hoon, C.D.; Jin, J.-I. Liquid crystalline aromatic polyesters. Polymer (Korea) 2005, 29, 523-535.

19. Jackson, W.J. Liquid crystalline polymers. 5. Liquid crystalline polyesters containing naphthalene rings. Macromolecules 1983, 16, 1027-1033. [CrossRef]

20. Blackwell, J.; Gutierrez, G. The structure of liquid crystalline copolyester fibers prepared from p-hydroxybenzoic acid, 2,6-dihydroxy naphthalene, and terephthalic acid. Polymer 1982, 23, 671-675. [CrossRef]

21. Koenig, J.L. Spectroscopy of Polymers; Elsevier: Amsterdam, The Netherland, 1999.

22. McBrierty, V.J.; Packer, K.J. Nuclear Magnetic Resonance in Solid Polymers; Cambridge University Press: Cambridge, UK, 2006.

23. Lim, A.R. Effects of paramagnetic interactions by the partial replacement of $\mathrm{Zn}^{2+}$ ions with $\mathrm{Cu}^{2+}$ ions in lead-free zinc-based perovskite (MA) ${ }_{2} \mathrm{ZnCl}_{4}$ crystal by MAS NMR. AIP Adv. 2019, 9, 105115. [CrossRef]

24. Damman, S.B.; Mercx, F.P.M.; Kootwijk-Damman, C.M. Liquid-crystalline main-chain polymers with a poly(p-phenylene terephthalate) backbone: 1 . Synthesis, characterization and rheology of polyesters with alkoxy side chains. Polymer 1993, 34, 1891-1897. [CrossRef]

25. Chang, J.-H.; Ju, C.H.; Kim, S.H. Synthesis and characterization of a series of thermotropic liquid crystalline copolyester nanocomposites. J. Polym. Sci. Part B Polym. Phys. 2006, 44, 387-397. [CrossRef]

26. Lim, A.R.; Chang, J.-H.; Kim, J.H.; Novak, B.M. Carbon-13 $\mathrm{T}_{1 \rho}$ investigation in two polycarbodiimides. Solid State Commun. 2000, 115, 23-28. [CrossRef]

27. Bershtein, V.A.; Yegorov, V.M.; Yemel'yanov, Y.A. Relations between the main relaxation transitions in polymers and the length of segments and the character and degree of cooperation in molecular motion in the vicinity of $\mathrm{T}_{\mathrm{g}}$. Polym. Sci. U.S.S.R. 1985, 27, 2757-2764. [CrossRef]

28. Chang, H.-S.; Wu, T.-Y.; Chen, Y. Synthesis and properties of TLCPs with 2,6-naphthalene-based mesogen, polymethylene spacer, and nonlinear 4,4'-thiodiphenyl links. J. Appl. Polym. Sci. 2002, 83, 1536-1546. [CrossRef]

29. Sakurai, T.; Nojima, S. Significant increase in the melting temperature of poly( $\varepsilon$-caprolactone) blocks confined in the crystallized lamellar morphology of poly( $\varepsilon$-caprolactone)- block -polyethylene copolymers. Polym. J. 2011, 43, 370-377. [CrossRef]

30. Jin, J.-I.; Kang, C.-S. Thermotropic main chain polyesters. Prog. Polym. Sci. 1997, 22, 937-973. [CrossRef]

31. Langelaan, H.C.; de Boer, A.P. Crystallization of thermotropic liquid crystalline HBA/HNA copolymers. Polymer 1996, 37, 5667-5680. [CrossRef] 
32. Ballauff, M. Rigid rod polymers having flexible side chains, 1 . Thermotropic poly(1,4-phenylene 2,5-dialkoxyterephthalate)s. Makromol. Chem., Rapid Commun. 1986, 7, 407-414. [CrossRef]

33. Hakemi, H. On the miscibility of liquid crystalline polymers. Polymer 2000, 41, 6145-6150. [CrossRef]

34. Wei, P.; Cakmak, M.; Chen, Y.; Wang, X.; Wang, Y.; Wang, Y. Aromatic liquid crystalline copolyesters with low $\mathrm{T}_{\mathrm{m}}$ and high $\mathrm{T}_{\mathrm{g}}$ : Synthesis, characterization, and properties. J. Appl. Polym. Sci. 2014, 131, 40487 (1-10). [CrossRef]

35. Chen, B.-K.; Tsay, S.-Y.; Chen, J.-Y. Synthesis and properties of liquid crystalline polymers with low $\mathrm{T}_{\mathrm{m}}$ and broad mesophase temperature ranges. Polymer 2005, 46, 8624-8633. [CrossRef]

36. Elias, F.; Clarke, S.M.; Peck, R.; Terentjev, E.M. Equilibrium textures in main-chain liquid crystalline polymers. Europhys. Lett. 1999, 47, 442-448. [CrossRef]

37. Jin, J.-I.; Chang, J.-H.; Shim, H.K. Properties of aromatic copolyesters derived from p-hydroxybenzoic acid, terephthalic acid, and naphthalenediol isomers. Macromolecules 1989, 22, 93-99. [CrossRef]

38. Shukla, U.; Rao, K.V.; Rakshit, A.K. Thermotropic liquid-crystalline polymers: Synthesis, characterization, and properties of poly(azomethine esters). J. Appl. Polym. Sci. 2003, 88, 153-160. [CrossRef]

39. Babacan, V.; Aksoy, S.; Yerlikaya, Z.; Altinok, H. Thermal and morphological properties of thermotropic liquid-crystalline copolyesters containing poly(ethylene terephthalate), 4-hydroxyphenylacetic acid and main-chain rigid aromatic units. Polym. Int. 2010, 59, 749-755. [CrossRef]

40. Lim, A.R.; Novak, B.M. Helix conformation in helical polycarbodiimides studied by solid state 13C NMR. Chem. Phys. 2001, 272, 199-212. [CrossRef]

41. Pouchert, C.J. The Aldrich Library of $13 C$ and 1 H FT NMR Spectra; Aldrich Publication: New York, NY, USA, 1993.

42. Jasinska-Walc, L.; Villani, M.; Dudenko, D.; van Asselen, O.; Klop, E.; Rastogi, S.; Hansen, M.R.; Koning, C.E. Local conformation and cocrystallization phenomena in renewable diaminoisoidide-based polyamides studied by FT-IR, solid state NMR, and WAXD, and WAXD. Macromolecules 2012, 45, 2796-2808. [CrossRef]

43. Abragam, A. The Principles of Nuclear Magnetism; Oxford University Press: Oxford, UK, 1961.

(C) 2020 by the authors. Licensee MDPI, Basel, Switzerland. This article is an open access article distributed under the terms and conditions of the Creative Commons Attribution (CC BY) license (http://creativecommons.org/licenses/by/4.0/). 